(c) 2020, The Authors. Published by FASS Inc. and Elsevier Inc. on behalf of the American Dairy Science Association ${ }^{\circledR}$. This is an open access article under the CC BY-NC-ND license (http://creativecommons.org/licenses/by-nc-nd/4.0/).

\title{
Predictive ability of host genetics and rumen microbiome for subclinical ketosis
}

\author{
Grum Gebreyesus, ${ }^{1 *} \dagger \oplus$ Gareth F. Difford, ${ }^{1,2 *} \odot$ Bart Buitenhuis, ${ }^{1}{ }^{\oplus}$ Jan Lassen, ${ }^{1}$ Samantha Joan Noel, ${ }^{3} \odot$

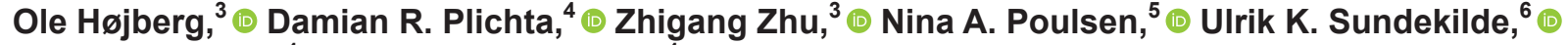 \\ Peter Løvendahl, ${ }^{1}{ }^{\circledR}$ and Goutam Sahana ${ }^{1}$ (이 \\ ${ }^{1}$ Center for Quantitative Genetics and Genomics, Aarhus University, DK-8830 Tjele, Denmark \\ ${ }^{2}$ Nofima (Norwegian Institute of Food, Fisheries and Aquaculture Research), 1432 Ås, Norway \\ ${ }^{3}$ Department of Animal Science, Aarhus University, DK-8830 Tjele, Denmark \\ ${ }^{4}$ Center for Biological Sequence Analysis, Denmark Technical University, DK-2800 Lyngby, Denmark \\ ${ }^{5}$ Department of Food Science, Aarhus University, DK-8830 Tjele, Denmark \\ ${ }^{6}$ Department of Food Science, Aarhus University, DK-5792 Arslev, Denmark
}

\begin{abstract}
Subclinical metabolic disorders such as ketosis cause substantial economic losses for dairy farmers in addition to the serious welfare issues they pose for dairy cows. Major hurdles in genetic improvement against metabolic disorders such as ketosis include difficulties in large-scale phenotype recording and low heritability of traits. Milk concentrations of ketone bodies, such as acetone and $\beta$-hydroxybutyric acid (BHB), might be useful indicators to select cows for low susceptibility to ketosis. However, heritability estimates reported for milk BHB and acetone in several dairy cattle breeds were low. The rumen microbial community has been reported to play a significant role in host energy homeostasis and metabolic and physiologic adaptations. The current study aims at investigating the effects of cows' genome and rumen microbial composition on concentrations of acetone and BHB in milk, and identifying specific rumen microbial taxa associated with variation in milk acetone and $\mathrm{BHB}$ concentrations. We determined the concentrations of acetone and BHB in milk using nuclear magnetic resonance spectroscopy on morning milk samples collected from 277 Danish Holstein cows. Imputed high-density genotype data were available for these cows. Using genomic and microbial prediction models with a 10 -fold resampling strategy, we found that rumen microbial composition explains a larger proportion of the variation in milk concentrations of acetone and BHB than do host genetics. Moreover, we identified associations between milk acetone and BHB with some specific bacterial and archaeal op-
\end{abstract}

Received October 31, 2019.

Accepted January 28, 2020

*These authors contributed equally to this work.

†Corresponding author: grum.gebreyesus@mbg.au.dk erational taxonomic units previously reported to have low to moderate heritability, presenting an opportunity for genetic improvement. However, higher covariation between specific microbial taxa and milk acetone and BHB concentrations might not necessarily indicate a causal relationship; therefore further validation is needed before considering implementation in selection programs.

Key words: microbial composition, milk acetone, BHB

\section{INTRODUCTION}

Intensive genetic selection for enhanced productivity over the past several decades has deteriorated most functional traits, leading to, among other problems, increased prevalence of metabolic diseases in highproducing dairy cattle breeds (Buckley et al., 2000; Boichard and Brochard, 2012). Subclinical metabolic disorders such as ketosis cause substantial economic losses for dairy farmers (Gohary et al., 2016), in addition to the welfare issues they pose for dairy cows (Oltenacu and Algers, 2005). With increasing public awareness of animal welfare as well as economic loses, calls have arisen for better attention to metabolic disorder traits in dairy cattle breeding goals (Boichard and Brochard, 2012; Pryce et al., 2016). However, the difficulties of large-scale phenotyping and low heritability remain major hurdles in genetic improvement of metabolic disorders such as ketosis.

Ketosis is among the most frequent disorders in dairy cattle (Koeck et al., 2014; Pryce et al., 2016). This disorder is characterized by the accumulation of ketone bodies, mainly BHB, acetoacetate, and acetone, which can be measured in the body fluids, including blood, urine, and milk (Geishauser et al., 1998). Ketosis may be clinical or subclinical depending on the presence or absence of clinical signs indicative of the disease (Cote 
et al., 1969). Subclinical ketosis cannot be observed but, rather, must be measured using indicators in body fluids. Conventionally, cows with at least one blood test of BHB concentration $>1.2 \mathrm{mmol} / \mathrm{L}$ (Geishauser et al., 1998; Jorritsma et al., 1998; McArt et al., 2012) or nonesterified fatty acid concentrations $>1.0 \mathrm{mM}$ (Raboisson et al., 2014) are declared to be in a state of subclinical ketosis. Heritability of subclinical ketosis based on such measurements has been reported in the range of 0.01 to 0.16 across several studies (Pryce et al., 2016). Strong correlations $(r>0.80)$ have been reported between concentrations of ketone bodies in the milk and in the blood (Andersson, 1984). Owing to the emergence of cheap and high-throughput methods to quantify detailed milk composition, such as Fouriertransform infrared spectroscopy (Heuer et al., 2001; de Roos et al., 2007), milk acetone and BHB levels have been suggested as useful indicators of subclinical ketosis (Nielsen et al., 2005; Boichard and Brochard, 2012).

Studies in mice and other model animals indicate that the gut microbial community plays a significant role in host energy homeostasis and metabolic and physiologic adaptations to periods of nutrient deprivation (Bäckhed et al., 2004; Crawford et al., 2009; Cotter et al., 2013). As early as the 1800s, the link between metabolic disorders and rumen contents was known to farmers in Europe, who would inoculate ruminant livestock that did not ruminate with the cud of healthy stock to stimulate rumination (DePeters and George, 2014). The bovine rumen harbors diverse communities of microbes, whose compositions are shaped by both diet and species of the host (Henderson et al., 2015). Zhu et al. (2018) demonstrated large changes in rumen bacteria and archaea composition in dairy cows over parturition and early lactation, when ketosis is most prominent. Difford et al. (2018) showed that certain bacteria and archaea taxa were associated with methane $\left(\mathrm{CH}_{4}\right)$ emissions in Holstein cows-observations recently confirmed in a multi-country, multi-breed study by Wallace et al. (2019). So far, however, the contribution of rumen microbial composition to variation in susceptibility to subclinical ketosis has not been studied in dairy cattle. If sizable proportions of the variation in subclinical ketosis can be explained by the relative abundance of rumen microbial taxa, especially those that are influenced by the host genotype (Difford et al., 2018), it might lead to a possibility of improving prediction for ketosis susceptibility.

Therefore, the objectives of this study were as follows: (1) to estimate the proportion of variation in the concentrations of BHB and acetone in milk explained by host genetics and rumen microbial composition; (2) to investigate the predictive value of the rumen microbiome in milk BHB and acetone concentrations; and (3) to identify rumen microbial taxa whose relative abundance is associated with BHB and acetone concentrations in milk.

\section{METHODS}

\section{Animals and Phenotypes}

Morning milk samples were collected once from 277 Danish Holstein cows that were at first and second parity, with DIM ranging between 3 and $517 \mathrm{~d}$. The cows belonged to 3 different commercial farms in Denmark with similar feeding regimens. Cows were fed TMR ad libitum and were milked individually in automated milking systems.

Milk samples were placed on ice immediately after sampling for transport to the laboratory, where the samples were aliquoted and skimmed, as described by Jensen et al. (2012). Skim milk samples were kept at $-80^{\circ} \mathrm{C}$ until further analysis.

Nuclear magnetic resonance (NMR) spectroscopy was performed as described previously by Sundekilde et al. (2013). Before NMR spectroscopy, skim milk samples were thawed and thoroughly shaken for homogenization. Samples were filtered to remove residual lipids and protein using an Amicon Ultra $0.5 \mathrm{~mL}, 10-\mathrm{kDa}$ cutoff spin filter (Millipore, Billerica, MA) at 10,000 $\times g$ for $30 \mathrm{~min}$. Four hundred microliters of filtered sample were mixed with $200 \mu \mathrm{L}$ of deuterium oxide $\left(\mathrm{D}_{2} \mathrm{O}\right)$ containing $0.025 \%$ sodium trimethylsilyl-[2,2,3,3$\left.{ }^{2} \mathrm{H}_{4}\right]$-1-propionate (Sigma-Aldrich, Brondby, Denmark), which served as an internal chemical shift reference. The ${ }^{1} \mathrm{H}$ NMR spectroscopy was performed at $298 \mathrm{~K}$ on a Bruker Avance III 600 spectrometer operating at a ${ }^{1} \mathrm{H}$ frequency of $600.13 \mathrm{MHz}$ and equipped with a 5-mm ${ }^{1} \mathrm{H}$ TXI probe (Bruker Biospin, Ettlingen, Germany). Standard 1-dimensional spectra were acquired using a single $90^{\circ}$ pulse experiment with a relaxation delay of $5 \mathrm{~s}$. Water suppression was achieved by irradiating the water peak during the relaxation delay, and a total of 64 scans were collected into 32,000 data points that spanned a spectral width of $12.15 \mathrm{ppm}$. Before Fourier transformation, the data were multiplied by a $0.3-\mathrm{Hz}$ line-broadening function. The proton NMR spectra were phase- and baseline-corrected manually using Topspin 3.0 (Bruker Biospin), and the NMR signals were assigned in accordance with existing literature, the Human Metabolome Database (http://www.hmdb .ca/), and the Biological Magnetic Resonance Data Bank (http://www.bmrb.wisc.edu/; Hu et al., 2004; Ulrich et al., 2008; Wishart et al., 2009; Klein et al., 2010). Relative quantification of the well-resolved reso- 
nances of acetone $(\delta 2.23 \mathrm{ppm} ; \mathrm{s}, 6 \mathrm{H})$ and $\mathrm{BHB}(\delta 1.20$ ppm; d, J $=6.29 \mathrm{~Hz}, 3 \mathrm{H}$ ) was performed in Matlab 7.9 (MathWorks Inc., Natick, MA).

\section{Rumen Sampling, DNA Extraction, Prokaryotic Sequencing Analysis}

Approximately $40 \mathrm{~g}$ of rumen content (both liquid and particle matter) was sampled with a flora rumen scoop before first feeding the same morning that milk samples were taken, and a representative subsample was immediately frozen to $-80^{\circ} \mathrm{C}$ for DNA extraction. The structure of the bacterial and archaeal community was assessed by sequencing the $16 \mathrm{~S}$ rRNA gene: the V1-V3 region for bacteria (27F: 5'-AGAGTTTGATCCTGGCTCAG-3', and 534R: 5'-ATTACCGCGGCTGCTGG-3') and the V4-V6 region for archaea (S-D-Arch-0519-a-S-15 5'-CAGCMGCCGCGGTAA-3' and S-D-Arch-1041-a-A-18 5'-GGCCATGCACCWCCTCTC-3'). Extraction of DNA and sequence library construction and sequencing were conducted at a commercial company (GATC Biotech, Constance, Germany). Sequences with lengths longer than $300 \mathrm{bp}$ were clustered into operational taxonomic units (OTU) based on $97 \%$ sequence similarity, using LotuS pipeline (Hildebrand et al., 2014). The average numbers of reads per sample were 136,561 for archaea and 118,268 for bacteria, resulting in 4,018 archaeal and 35,477 bacterial OTU. Taxonomy was assigned to each OTU using the RDP classifier (Wang et al., 2007) with a confidence level of 0.8, using greengenes (gg_13_8_otus) as the reference database (http://www.metagenomics.wiki/ tools/16s/qiime/install/greengenes). After taxonomic classification, $76.4 \%$ of archaea and $42.5 \%$ of bacteria were assigned at genus level. Details of rumen sampling, DNA extraction, library generation, and community analysis are previously described in Difford et al., 2018.

\section{Genotyping}

All sampled cows were genotyped with the BovineSNP50 BeadChip (Illumina, San Diego, CA) using an Illumina Infinium II Multisample assay device. Genomic DNA was extracted from ear tissue. Genotypes were subject to quality control, including (1) minimum call rates of $90 \%$ for individuals and $95 \%$ for loci and (2) exclusion of SNP with a minor allele frequency lower than $5 \%$ before imputation to Illumina BovineHD markers using IMPUTE2, v. 2.3.1 (Howie et al., 2011). Imputation was based on a reference population of 3,383 animals, including sires and siblings of some of the sampled cows, as described in detail by Gebreyesus et al. (2016). Imputation accuracies were assessed based on the built-in cross-validation system implemented in IMPUTE2, which showed that imputation error was, on average, less than 1\%. Finally, 436,000 SNP across the 29 bovine autosome were available for the analyses. Markers in the bovine X chromosome were not available in our original data set for the imputation; therefore, these were not included for either the parameter estimation or the genomic prediction analyses.

\section{Computation of Relationship Matrices}

The genomic relationship matrix was calculated following VanRaden's method-1 (VanRaden, 2008). The microbial relationship matrix (M) was computed based on bacteria counts, as previously described by Difford et al. (2018): $\mathbf{M}=\mathbf{X} \mathbf{X}^{\prime} / n$, where $\mathbf{X}$ is the matrix of natural log transformed bacterial and archaeal relative abundance for all animals and is computed as follows: bacterial and archaeal count matrix are screened for OTU present in at least $50 \%$ of the samples, resulting in 4,018 bacterial and 208 archaeal OTU. Thresholds for OTU incidence are somewhat arbitrary, selected across literature, ranging from 5 to $80 \%$ (Benson et al., 2010; Rothschild et al., 2018). Most commonly a threshold of $50 \%$ is employed, as presence versus absence can be seen as a binary trait, and a $50 \%$ threshold is the point at which the variance of binary traits is maximized (Goodrich et al., 2014; Difford et al., 2018; Fan et al., 2019). Bacterial and archaeal OTU are then natural log-transformed after the addition of a small constant 0.01 ( $1 \%$ of the lowest possible count 1 ), which is then centered and scaled; $\mathrm{n}$ is the number of bacterial and archaeal OTU.

\section{Statistical Models}

We compared prediction accuracies for BHB and acetone concentrations in milk, using models that include either genomic or microbial relationship matrices. The models are described as follows:

$$
\begin{gathered}
y_{i j k l}=\mu+\text { parity }_{i}+\text { herd }_{j}+b_{1} \text { DIM }_{k} \\
+b_{2} \times \exp ^{-0.05 \times D I M_{k}}+g_{l}+e_{i j k l} \\
y_{i j k l}=\mu+\text { parity }_{i}+\text { herd }_{j}+b_{1} \text { DIM }_{k} \\
+b_{2} \times \exp ^{10.05 \times D I M_{k}}+m_{l}+e_{i j k l},
\end{gathered}
$$

where $y_{i j k l}$ is the phenotype of cow $l$ in parity $i$ and herd $j ; \mu$ is the fixed intercept effect; $b_{1}$ is the regression coefficient for $D I M_{k}$, which is a covariate describing the ef- 
fect of DIM; $b_{2}$ is the regression coefficient for the Wilmink adjustment $\left(\exp ^{-0.05 \times D I M_{k}}\right)$ of DIM (Wilmink, 1987); $e_{i j k l}$ is a random residual effect assumed normally distributed with $\mathbf{e} \sim N\left(0, \mathbf{I}_{e}^{2}\right)$, where $\mathbf{I}$ is an identity matrix. Additionally, $g_{l}$ is the random additive genetic effect of the animal, $m_{l}$ is the random effect associated with microbial count, and $e_{i j k l}$ is the random residual effect. The random effects $g_{l}$ and $m_{l}$ are assumed to be independent and normally distributed as follows: $\mathbf{g} \sim N\left(0, \mathbf{G} \sigma_{a}^{2}\right)$ and $\mathbf{m} \sim N\left(0, \mathbf{M} \sigma_{m}^{2}\right)$, where $\mathbf{G}$ is the genomic relationship matrix between individuals and $\sigma_{a}^{2}$ is the additive genetic variation, and $\mathbf{M}$ is the microbial relationship matrix with $\sigma_{m}^{2}$ microbial variation.

The proportion of the total phenotypic variance explained by additive genetic effects (heritability) was computed as

$$
h^{2}=\sigma_{a}^{2} /\left(\sigma_{a}^{2}+\sigma_{e}^{2}\right)
$$

where $\sigma_{a}^{2}$ was the additive genetic variation, and $\sigma_{e}^{2}$ was the residual variation.

The proportion of the total phenotypic variance explained by rumen microbial composition, also called microbiability (Difford et al., 2018), was defined as

$$
m^{2}=\sigma_{m}^{2} /\left(\sigma_{m}^{2}+\sigma_{e}^{2}\right),
$$

where $\sigma_{m}^{2}$ was the variation explained by the microbial composition and $\sigma_{e}^{2}$ was the residual variation. The parameters $\sigma_{g}^{2}$ and $\sigma_{m}^{2}$ were estimated based on Models [1] and [2], respectively, and the average values of the 10 replicates were used. Analyses were performed using DMU software (Madsen and Jensen, 2007).

\section{Cross-Validation and Predictive Ability of the Models}

In both prediction models, a resampling strategy using cows in 10 validation sets was implemented to compare the 2 models for prediction reliability. In each resampled analysis, 50 cows were randomly selected to create each of the 10 validation sets, which had a certain amount of random overlaps in assigned cows. For the model with random genetic effects (Model [1]), prediction reliability was computed as the squared average correlation between genomic EBV and the phenotype corrected for fixed effects, from 10 replicates, divided by heritability estimates. Similarly, for the model with random effect of rumen microbial content (Model [2]), prediction reliability was computed as the squared average correlation between estimated microbial value and the phenotype corrected for fixed effects, divided by microbiability estimates.

\section{Association Between Rumen Bacterial and Archaeal OTU and BHB and Acetone}

The association between the relative abundance of each bacterial and archaeal OTU with BHB and acetone was calculated using Model [1], where the effect of fixed regression of each OTU was estimated separately for each of the 203 archaeal and 4,394 bacterial OTU that were present in at least $50 \%$ of cows. The significance threshold was calculated using a Bonferroni correction for multiple testing at $\alpha=0.05$, corresponding to a $-\log _{10} P$-value of 4.92 .

\section{RESULTS}

\section{Milk BHB and Acetone}

Table 1 presents the descriptive statistics of milk BHB and acetone in Danish Holstein cows quantified by integration of NMR resonances. A high coefficient of variation (CV) was computed for acetone (1.24), whereas the CV for BHB was moderate (0.59). Figure 1 shows milk concentrations of acetone (A) and BHB (B) plotted against DIM. Peak concentrations of both acetone and BHB in the milk appeared early in lactation $(<50$ DIM $)$.

\section{Parameter Estimates}

Table 2 shows the variances explained by host genetics and rumen microbial composition along with heritability and microbiability estimates. In general, heritability estimates were quite low for both traits $\left(\mathrm{h}^{2}\right.$ $=0.10$ for acetone and 0.03 for BHB). In comparison, relatively higher microbiability values were estimated for both acetone and BHB $\left(\mathrm{m}^{2}=0.15\right)$. For all parameter estimates except microbiability, the standard errors of estimation were generally higher than the parameter estimates.

Table 1. Descriptive statistics of milk acetone and BHB in Danish Holstein cows

\begin{tabular}{lcccc}
\hline Metabolite & Mean & CV & $5 \%$ quantile & $95 \%$ quantile \\
\hline Acetone & 0.57 & 1.24 & 0.21 & 1.10 \\
BHB & 0.89 & 0.59 & 0.41 & 1.64 \\
\hline
\end{tabular}


Table 2. Genetic and rumen microbial composition parameter estimates with standard errors for acetone and $\mathrm{BHB}^{1}$

\begin{tabular}{lllll}
\hline Metabolite & $\sigma_{a}^{2}( \pm \mathrm{SE})$ & $\sigma_{m}^{2}( \pm \mathrm{SE})$ & $h^{2}( \pm \mathrm{SE})$ & $m^{2}( \pm \mathrm{SE})$ \\
\hline Acetone & $0.03(0.19)$ & $0.03(0.11)$ & $0.10(0.14)$ & $0.15(0.09)$ \\
BHB & $0.0075(0.16)$ & $0.017(0.09)$ & $0.03(0.13)$ & $0.15(0.07)$ \\
\hline
\end{tabular}

${ }^{1} \sigma_{a}^{2}=$ additive genetic variance; $\sigma_{m}^{2}=$ proportion of variance explained by rumen microbial composition; $m^{2}$ $=$ microbiability.

\section{Predictability of Milk BHB and Acetone Contents}

Prediction reliabilities for BHB and acetone using host genetics and rumen microbial composition are shown in Figure 2. Using host genetics as the predictor, acetone showed relatively higher predictability (average reliability $=0.25$ ) than $\mathrm{BHB}$ (average reliability $=0.02$ ). Using rumen microbial composition as the

(A)

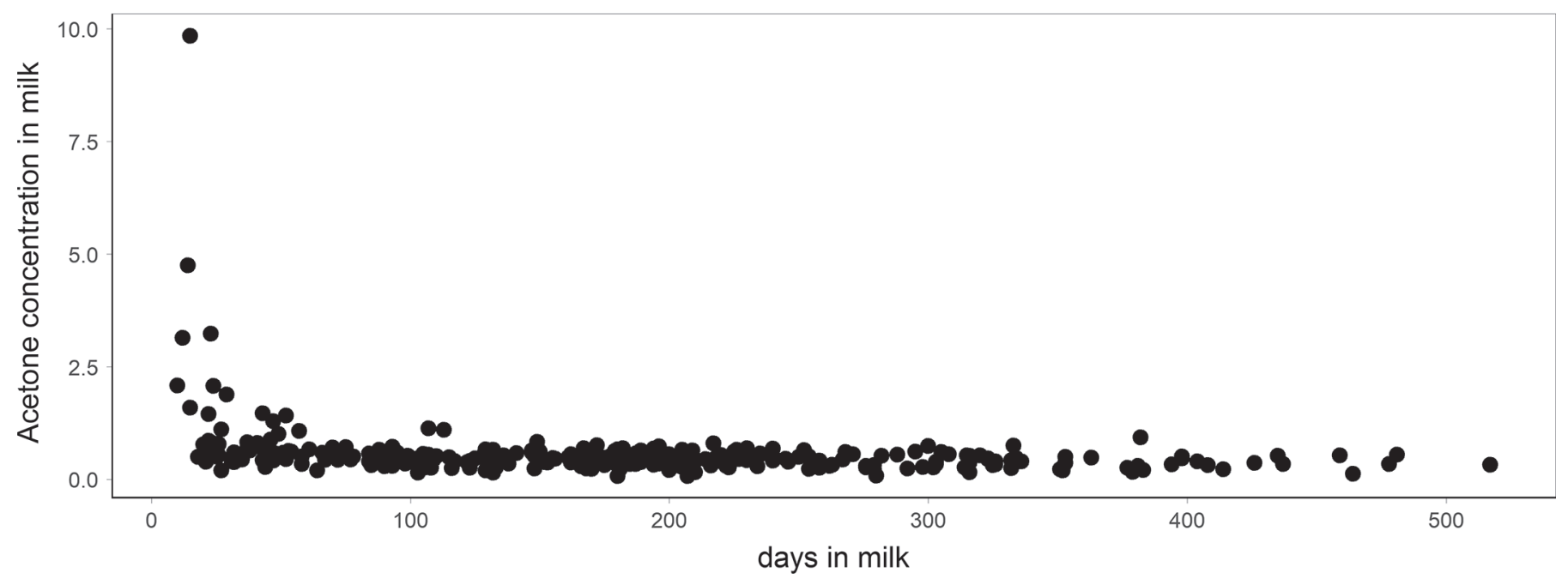

(B)

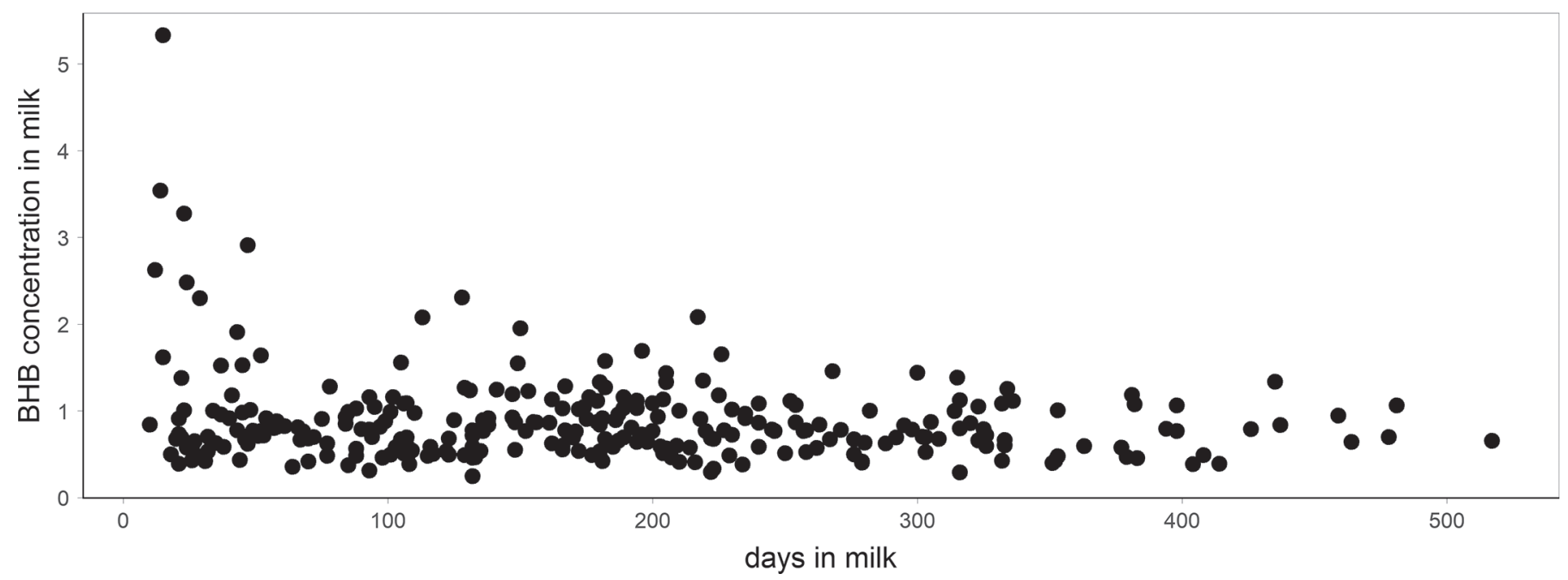

Figure 1. Milk concentrations of acetone (A) and BHB (B) across days in milk. 
predictor improved prediction reliability substantially for both $\operatorname{BHB}(\Delta=0.53)$ and acetone $(\Delta=0.10)$ compared with the model using host genetics for prediction.

Reported prediction reliabilities are based on average correlations between genomic EBV, or estimated microbial value, and the corrected phenotype from the 10 cross-validation replicates, which generally showed lower deviations from the averages across the models and in both traits. The mean absolute deviations in prediction reliability of the 10 replicates from the reported averages were 0.07 for the model using genomic relationships in both acetone and BHB, as well as for the model based on microbes in BHB, whereas the corresponding value for the model using microbes for acetone was 0.12 .

\section{Rumen Microbe Composition Associated with $B H B$ and Acetone}

The top OTU from the microbial-wide association on BHB and acetone in milk can be found in Table 3. A total of 21 OTU were found to be associated with BHB (Figure 3) and 23 with acetone (Figure 4), exceeding the stringent Bonferroni threshold for multiple testing significance. Among those, 11 OTU were found in common between BHB and acetone. (See Supplemental File S1 for top OTU using the less-stringent false discovery rate of 1\%: https://doi.org/10.3168/jds.2019-17824). The bacterial OTU found to be highly significantly associated were predominantly members of the Prevotellaceae and Ruminococcaceae families, whereas the most significantly associated archaeal OTU were members of the genus Methanobrevibacter. All of the top bacterial OTU were depleted in relative abundance with increasing levels of BHB and acetone, whereas the archaeal

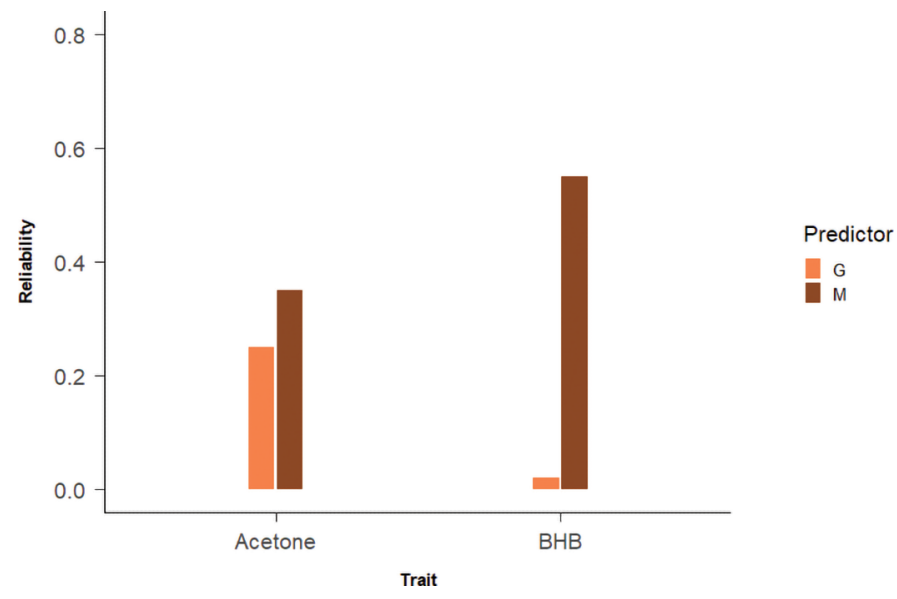

Figure 2. Prediction reliability for milk BHB and acetone concentrations using host genetics $(\mathrm{G})$ or rumen microbial composition $(\mathrm{M})$ as predictors.
OTU showed enrichment in relative abundance with increasing levels of BHB and acetone.

\section{DISCUSSION}

This study investigated the potentials of cow genetics and rumen microbial composition to predict milk concentrations of 2 major ketone bodies, acetone and BHB. Using milk concentrations of ketone bodies will allow a noninvasive method for diagnosis of subclinical ketosis that can be part of routine application. Methods have been developed to predict blood concentrations of ketone bodies using infrared-predicted milk BHB and acetone (e.g., Chandler et al., 2018). If substantial genetic variation is detectable in the milk composition of BHB and acetone, this will open a new avenue for selection against susceptibility to subclinical ketosis, using milk BHB and acetone as indicator traits. Apart from genetic differences between cows, differences in composition of the rumen microbial community might contribute to variation in milk metabolite concentrations. Quantification of the relative contributions of host genetics and rumen microbiome to variations in milk metabolite concentrations, and identification of the specific rumen microbial populations associated with these traits, might allow better prediction of genetic merits for resistance to subclinical ketosis.

\section{Effects of Host Genetics and Rumen Microbiome in Milk Metabolite Concentrations}

Differences between cows in metabolic adaptation to negative energy balance underlies differences in susceptibility to ketosis. Part of this difference can be attributed to genetics. In this study, we showed that the additive genetic variation constitutes only a small proportion of the variation in milk concentration of the major ketone bodies, BHB and acetone. The heritability estimate for BHB concentration was close to 0 , in agreement with reports from several previous studies. Lee et al. (2016), for instance, reported heritability values ranging between 0.04 and 0.17 for milk BHB in Korean Holstein cows, depending on parity and stage of lactation. Similarly, heritability values ranging between 0.07 and 0.29 were reported for milk BHB in several other studies for different breeds of cattle (van der Drift et al., 2012; Koeck et al., 2014; Penasa et al., 2015; Jamrozik et al., 2016). An exception to these reports was a higher heritability estimate reported by Buitenhuis et al. (2013) for milk BHB $\left(\mathrm{h}^{2}=0.87\right)$ using cows that were all sampled in mid-lactation. The heritability value estimated in our study for milk acetone $\left(\mathrm{h}^{2}=\right.$ $0.10)$ was generally lower than estimates from previous studies, which were in the range of 0.22 to 0.31 (Lee et 
al., 2016; Ranaraja et al., 2018). Generally, heritability estimates for milk concentration of ketone bodies might vary between studies depending on stages of lactation of sampled cows. Ketosis occurs early in lactation, and, thus, concentration of ketone bodies in milk drops in later stages of the lactation trajectory. In Figure 1, we show that acetone and BHB concentrations are very low in later stages of lactation $(>50 \mathrm{~d})$. Therefore, an ideal sampling strategy for genetic parameter estimation would be to focus on cows in the early stage of lactation. In our study, lactation stages of sampled cows ranged between 3 and 517 DIM, which may explain the difference in heritability estimates from some previous studies, and which might be considered a limitation of the current study.

In contrast to host genetics, the proportion of variation explained by cows' rumen microbial composition was higher for both BHB and acetone concentrations in milk $\left(\mathrm{m}^{2}=0.15\right)$. This finding suggests that rumen microbial composition might be more informative than host genetics in prediction of susceptibility to metabolic disorders using milk concentration of ketone bodies in cows. The microbiability estimated from fecal bacterial composition has been shown to be highly informative for predicting body mass index, glycemic status, and fasting glucose levels in humans (Rothschild et al., 2018). Similarly the $\mathrm{m}^{2}$ for feed conversion efficiency and feed intake in pigs exceeded $\mathrm{h}^{2}$ estimates for these 2 traits (Camarinha-Silva et al., 2017). Although $\mathrm{m}^{2}$ from rumen bacteria was found to be more informative than heritability in 5 of the 17 fatty acids tested in bovine milk, crucially these include the essential fatty acids linoleic acid (C18:2n-6) and $\alpha$-linolenic acid (C18:3n -3) (Buitenhuis et al., 2019). In the studies discussed above, $\mathrm{m}^{2}$ is estimated and contrasted with $\mathrm{h}^{2}$ to assess the relative importance of additive genetics and hostassociated microbial composition with variation in host phenotypes. Difford et al. (2018) further examined the shared information between the 2 effects by fitting in their model both genomic and microbial relationship matrices jointly; they reported negligible changes in the estimates of $\mathrm{h}^{2}$ and $\mathrm{m}^{2}$ compared with fitting each effect

Table 3. Top operational taxonomic units (OTU) associated with milk acetone and BHB concentrations ${ }^{1}$

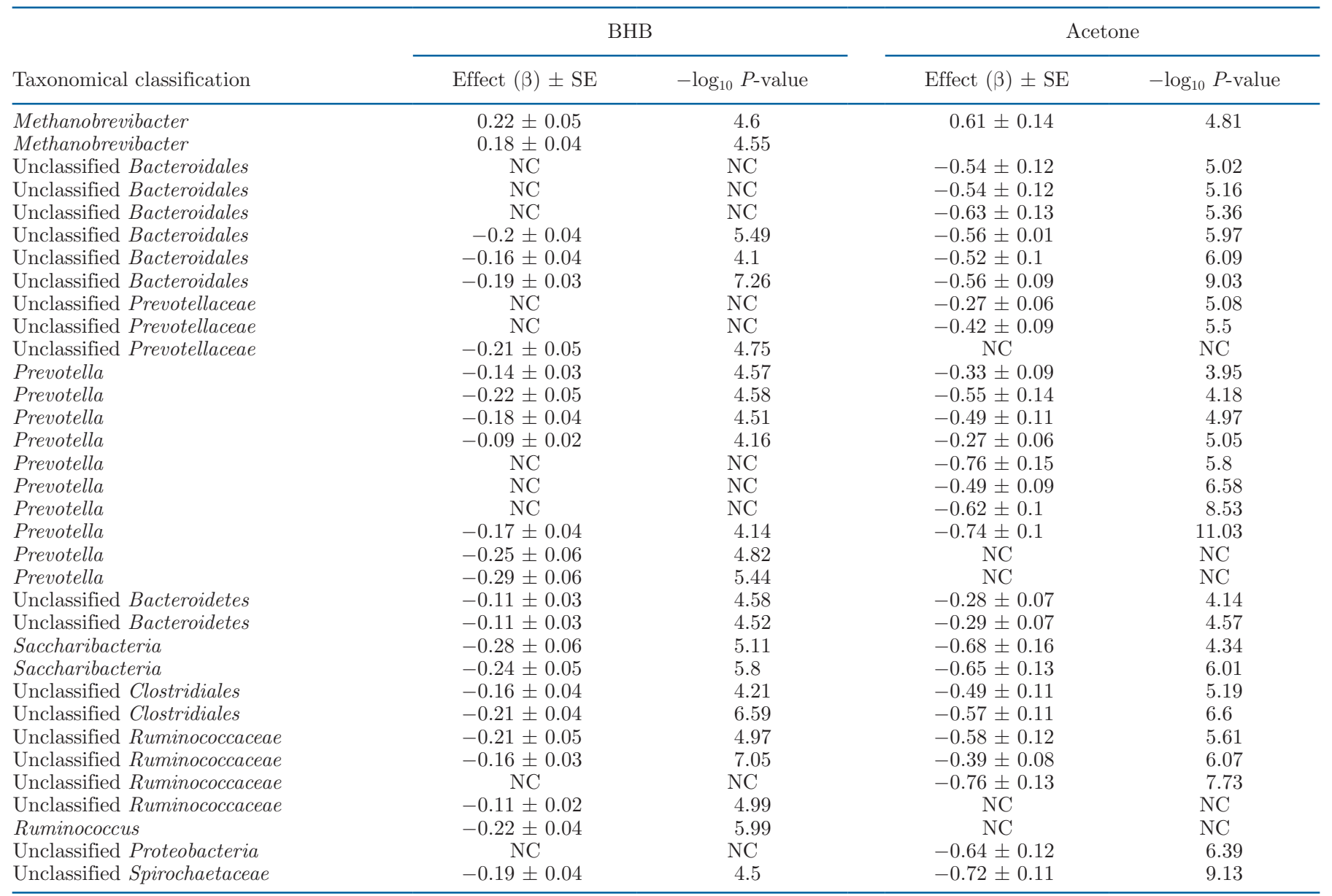

${ }^{1} \mathrm{NC}=$ nonconvergence of linear mixed model. Bonferroni threshold for multiple testing significance: $-\log _{10}(P)=4.92$. 


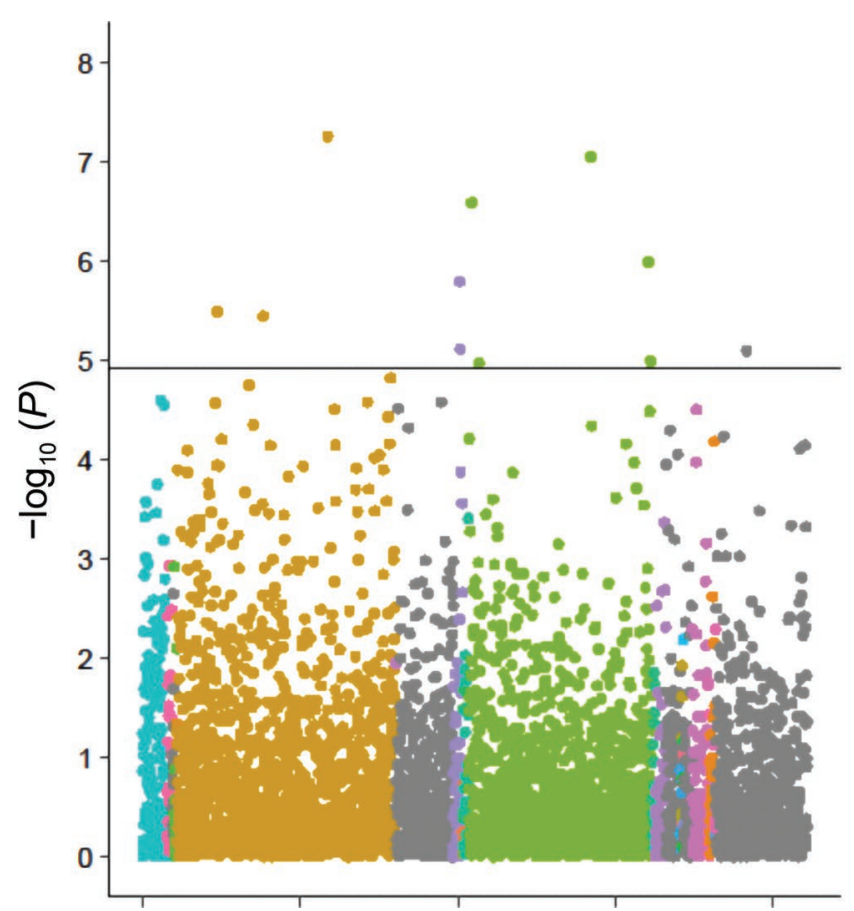

order

- Aeromonadales

- Anaerolineales

- Anaeroplasmatales

- Armatimonadetes_gp2

- Bacteroidales

- Burkholderiales

- Campylobacterales

- Candidatus Endomicrobium

- Clostridiales

- Coriobacteriales

- Desulfobacterales

- Desulfovibrionales

- Elusimicrobiales

- Erysipelotrichales

- Fibrobacterales

- Lactobacillales

- Methanobacteriales
- Methanosarcinales

- Neisseriales

- Oligosphaerales

- Planctomycetales

- Puniceicoccales

- Rhodospirillales

- Saccharibacteria genera incertae sedis

- Selenomonadales

- Sphingobacteriales

- Spirochaetales

- SR1_genera_incertae_sedis

- Subdivision5_genera incertae sedis

- Synergistales

- Thermoplasmatales

- Xanthomonadales

- NA

Figure 3. Manhattan plot of rumen bacterial and archaeal operational taxonomic unit (OTU) associations with milk acetone concentration. The y-axis is $-\log _{10}(P)$ for association tests. The horizontal line represents the Bonferroni threshold $(\alpha=0.05)$ for multiple testing significance: $-\log _{10}(P)=4.92$.

separately for $\mathrm{CH}_{4}$ production. Similarly, fitting both genomic and microbial relationship matrices jointly in our study led to negligible changes in estimates of $h^{2}$ and $\mathrm{m}^{2}$ compared with fitting the 2 effects separately (results not shown).

The rumen microbial ecosystem can exhibit 2 or more steady states under the same conditions, often referred to as ruminotypes (Kittelmann et al., 2014). Microbial ecosystems may switch between states due to perturbations such as removal of species through antibiotics or introduction of new species, as well as changes in environmental conditions (Faust et al., 2015). Dysbiosis occurs when host-associated microbial communities are sufficiently perturbed that the symbiotic relationship between host and microbes is disrupted; this can result in diseases. In humans, dysbiosis in the gut microbiota is known to alter host energy balance and feeding behavior and to cause chronic inflammation leading to, or aggravating, metabolic disorders (Lynch and Pedersen, 2016; Gilbert et al., 2018; Mulders et al., 2018). In cattle, metabolic diseases such as subacute ruminal acidosis have been associated with rumen microbial dysbiosis (Khafipour et al., 2009), but, as far as we can tell, subclinical ketosis has not. It is important to note that unlike $\mathrm{h}^{2}, \mathrm{~m}^{2}$ is a measure of covariance that has no inherent causal meaning. Thus, a higher $\mathrm{m}^{2}$ indicates an association between a phenotype and rumen microbial community composition, but controlled dose-response studies such as transfaunation experiments are needed to confirm a causal link between subclinical ketosis and rumen prokaryotic composition (Malmuthuge and Guan, 2017; Bickhart and Weimer, 2018).

\section{Predictability of Milk Metabolite Concentrations}

We found low reliability of predicting the metabolic indicator traits of milk BHB and acetone using cow's genotype. This might be primarily due to the low reference population size used in the prediction. The effect of reference population size on genomic prediction accuracy is well established (Daetwyler et al., 2008; Goddard, 2009). We assessed for possible effects of significant population substructures in the sample herds through principal component analysis of the genomic relationships between sampled animals. Our results indicate no evidence of such structure, with the first and second principal components together explaining merely $12.59 \%$ of the variation (results not shown). Compared with BHB, prediction reliability for milk acetone using cow genetics was relatively higher, in line with the heritability estimates for the 2 traits.

With the same reference sample size, we computed moderate to high prediction reliabilities for the traits using the microbial relationship matrix. Prediction 
reliability improved by 53 percentage points for BHB when microbial composition of the rumen was used in the prediction compared with using host genetics. The proportion of the variation in both milk BHB and acetone concentrations explained by rumen microbial composition was shown to be substantially higher than the proportion explained by host genetics. Therefore, the finding of higher prediction reliability using the microbial relationship matrix is in line with the measured effects of the rumen microbial composition.

The first attempts at host phenotype prediction using associated microbiota were conducted using a microbial relationship matrix derived from full metagenomic sequences; these demonstrated prediction accuracies in excess of 0.45 with as few as 30 cows in the reference population (Ross et al., 2013). Similarly, in a larger study in pigs $(\mathrm{n}=207)$, Camarinha-Silva et al. (2017) used fecal microbiota based on 16S rRNA gene sequencing to predict feed intake, daily gain, and feed conversion ratio, and found the accuracies of prediction based on microbial relationships $(0.33$ to 0.41$)$ to be higher than those based on genomic relationships $(0.20$ to 0.35 ) and to have lower standard errors. Maltecca et al. (2019) used Bayesian and machine-learning prediction models to predict fat and average daily gain using fecal microbial profiles in 1,043 pigs and achieved accuracies in the range of 0.40 to 0.50 . More recently, the RuminOmics Consortium used microbial relationship matrices and 16S rRNA gene profiling to predict numerous phenotypes in diverse European dairy cattle breeds and found prediction accuracies for blood BHB concentration to range from 0.33 in Finnish Aryshire $(\mathrm{n}=100)$ to 0.47 in UK Holsteins $(\mathrm{n}=297$; Wallace et al., 2019).

\section{Association of Rumen Prokaryotes with $B H B$ and Acetone}

We estimated associations between the abundance of rumen bacterial and archaeal OTU with milk BHB and acetone concentrations. The most strongly associated bacterial OTU are dominated by members of the families Prevotellaceae and Ruminococcaeae, both of which have shown negative associations with blood plasma levels of BHB (Schären et al., 2018; Wallace et al., 2019), negative energy balance (Derakhshani et al., 2017), and feed efficiency metrics such as residual energy intake and residual feed intake (Jami and Mizrahi, 2012; Shabat et al., 2016; Sasson et al., 2017). This is important because residual feed intake and residual energy intake are mathematically equivalent to negative energy balance and therefore potentially estimators of

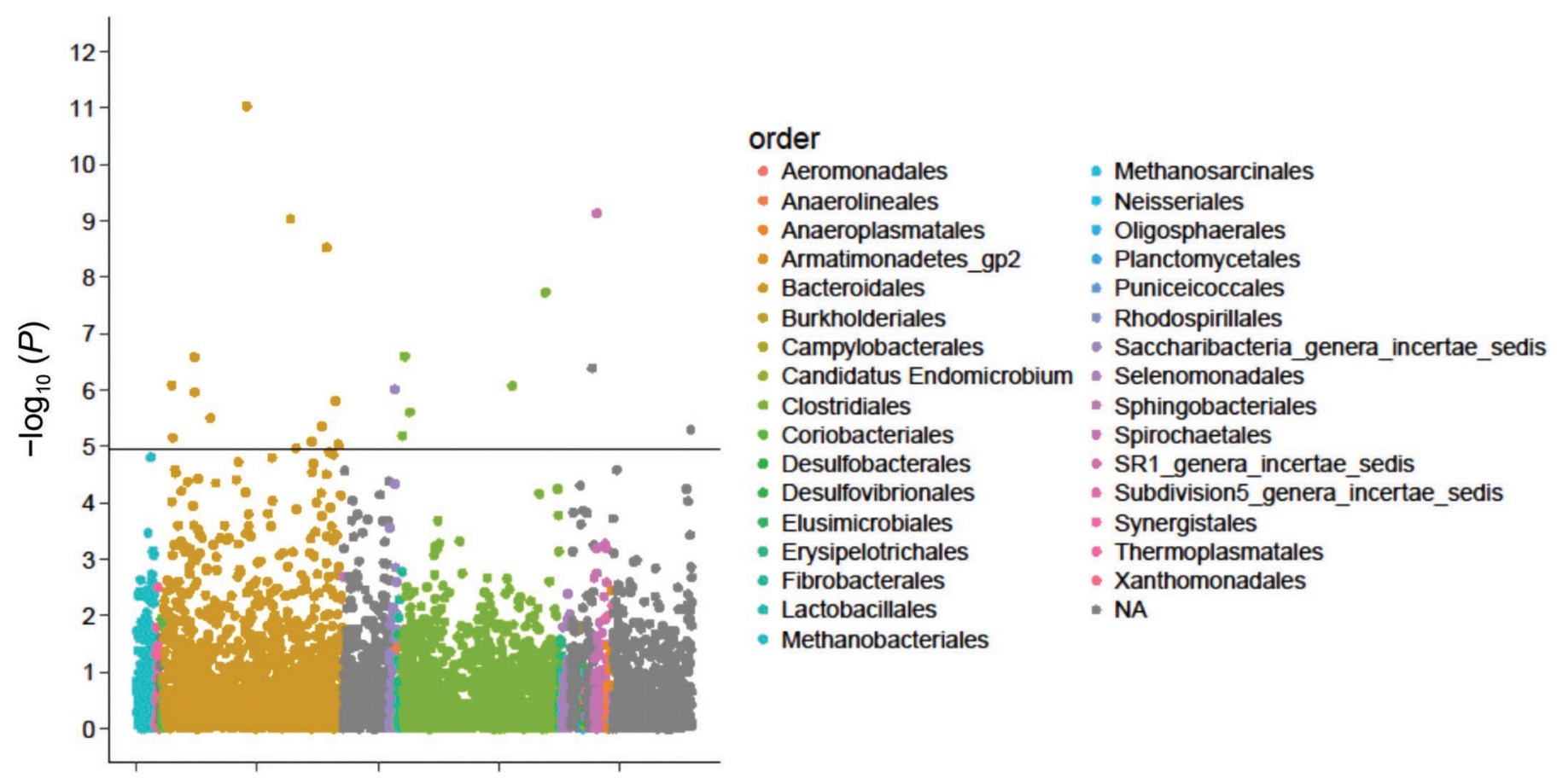

Figure 4. Manhattan plot of rumen bacterial and archaeal operational taxonomic unit (OTU) associations with milk BHB concentration. The y-axis is $-\log _{10}(P)$ for association tests. The horizontal line represents the Bonferroni threshold $(\alpha=0.05)$ for multiple testing significance: $-\log _{10}(P)=4.92$. 
subclinical ketosis, when mobilization of fat reserves is not taken into account in their calculation (Veerkamp, 2002).

Interestingly, the only archaeal OTU to show a positive association with milk BHB or acetone concentrations were members of the genus Methanobrevibacter. Although cultured representatives of this genera are known to produce methane primarily from $\mathrm{H}_{2}$ and $\mathrm{CO}_{2}$ as well as ethanol and formate (Leahy et al., 2010), the relationship with ketosis substrates is not immediately apparent. Methanobrevibacter species have been associated with ketosis and obesity in mice (Turnbaugh et al., 2006; Newell et al., 2016) as well as in humans (Armougom et al., 2009; Million et al., 2013), where it is hypothesized their hydrogen consumption maintains optimal conditions of anaerobic fermentation. Milk acetone concentrations have been associated with decreased methane emissions in dairy cows (AntunesFernandes et al., 2016), and Methanobrevibacter species have been associated with residual feed intake in beef steers (Zhou et al., 2009), as well as ruminal $\mathrm{pH}$ (Schären et al., 2018), indicating a possible link between subclinical ketosis, capacity to harvest energy, and methane production. Although Prevotellaceae, Ruminococcaeae, and Methanobrevibacter have been shown to be heritable in the range of 0 to 0.32 (Difford et al., 2018; Li et al., 2019; Wallace et al., 2019), we caution against selection until the relationships between rumen prokaryotes, methane production, feed efficiency, and ketosis are elucidated.

\section{CONCLUSIONS}

This study examined the predictive abilities of cows' genetics and rumen microbial composition for milk concentrations of the major ketone bodies, acetone and BHB. In general, our findings suggest an important predictive ability of the rumen microbial composition with regard to dairy cows' milk BHB and acetone concentrations. The group of OTU found to have significant association with milk BHB and acetone concentration in this study were previously reported to have low to moderate heritability, presenting an opportunity for selective breeding. However, higher covariation between microbial composition and milk metabolite concentration might not necessarily indicate causation. Further studies are needed to confirm whether such causative relationships do exist and to unravel the underlying mechanisms.

\section{ACKNOWLEDGMENTS}

This research was supported by the projects: "The importance of the metagenome for milk quality and composition" of the Danish Milk Levy Fund (2013 to 2015), as well as from the REMRUM project from the Innovation Fund Denmark (formerly the Danish Council for Strategic Research; Copenhagen) for funding support (grant number 12-132447). All procedures to collect the samples followed the protocols approved by the National Guidelines for Animal Experimentation and the Danish Animal Experimental Ethics Committee, and all handling of animals was conducted according to "Metagenomics in Dairy Cows" protocol. Milk sampling was restricted to routine on-farm procedures that did not cause any inconvenience or stress to the animals; hence, no specific permission was required. Rumen liquid sampling protocol and applied procedures were approved by the Animal Experiments Inspectorate, Danish Veterinary and Food Administration, Ministry of Environment and Food of Denmark (Copenhagen; approval number 2016-15-0201-00959). The authors' contributions are as follows. Drafted manuscript: GG and GFD; analyzed data: GG and GFD; collected milk samples: NP; performed NMR: UKS; collected rumen samples: ZZ, GFD, PL, and JL; processed sequence data SJN and DP; processed genotype data: GG; conceived design of study: AJB, NP, OH, PL, JL, and GS; attracted funding: AJB, NP, and PL. The authors have stated no conflicts of interest.

\section{REFERENCES}

Andersson, L. 1984. Concentrations of blood and milk ketone bodies, blood isopropanol, and plasma glucose in dairy cows in relation to the degree of hyperketonaemia and clinical signs. Zentralbl. Veterinarmed. A 31:683-693. https://doi.org/10.1111/j.1439-0442.1984 .tb01327.x.

Antunes-Fernandes, E. C., S. van Gastelen, J. Dijkstra, K. A. Hettinga, and J. Vervoort. 2016. Milk metabolome relates enteric methane emission to milk synthesis and energy metabolism pathways. J. Dairy Sci. 99:6251-6262. https://doi.org/10.3168/jds.2015-10248.

Armougom, F., M. Henry, B. Vialettes, D. Raccah, and D. Raoult. 2009. Monitoring bacterial community of human gut microbiota reveals an increase in Lactobacillus in obese patients and Methanogens in anorexic patients. PLoS One 4:e7125. https://doi.org/10 .1371 /journal.pone.0007125.

Bäckhed, F., H. Ding, T. Wang, L. V. Hooper, G. Y. Koh, A. Nagy, C. F. Semenkovich, and J. I. Gordon. 2004. The gut microbiota as an environmental factor that regulates fat storage. Proc. Natl. Acad. Sci. USA 101:15718-15723. https://doi.org/10.1073/pnas .0407076101.

Benson, A. K., S. A. Kelly, R. Legge, F. Ma, S. J. Low, J. Kim, M. Zhang, P. L. Oh, D. Nehrenberg, K. Hua, S. D. Kachman, E. N. Moriyama, J. Walter, D. A. Peterson, and D. Pomp. 2010. Individuality in gut microbiota composition is a complex polygenic trait shaped by multiple environmental and host genetic factors. Proc. Natl. Acad. Sci. USA 107:18933-18938. https://doi.org/10 .1073 pnas.1007028107.

Bickhart, D. M., and P. J. Weimer. 2018. Symposium review: Host-rumen microbe interactions may be leveraged to improve the productivity of dairy cows. J. Dairy Sci. 101:7680-7689. https://doi.org/ 10.3168/jds.2017-13328.

Boichard, D., and M. Brochard. 2012. New phenotypes for new breeding goals in dairy cattle. Animal 6:544-550. https://doi.org/10 $.1017 /$ S1751731112000018. 
Buckley, F., P. Dillon, M. Rath, and R. F. Veerkamp. 2000. The relationship between genetic merit for yield and live weight, condition score, and energy balance of spring calving Holstein Friesian dairy cows on grass based systems of milk production. J. Dairy Sci. 83:1878-1886.

Buitenhuis, A. J., U. K. Sundekilde, N. A. Poulsen, H. C. Bertram, L. B. Larsen, and P. Sørensen. 2013. Estimation of genetic parameters and detection of quantitative trait loci for metabolites in Danish Holstein milk. J. Dairy Sci. 96:3285-3295. https://doi.org/ 10.3168/jds.2012-5914.

Buitenhuis, B., J. Lassen, S. J. Noel, D. R. Plichta, P. Sørensen, G. F. Difford, and N. A. Poulsen. 2019. Impact of the rumen microbiome on milk fatty acid composition of Holstein cattle. Genet. Sel. Evol. 51:23. https://doi.org/10.1186/s12711-019-0464-8.

Camarinha-Silva, A., M. Maushammer, R. Wellmann, M. Vital, S. Preuss, and J. Bennewitz. 2017. Host genome influence on gut microbial composition and microbial prediction of complex traits in pigs. Genetics 206:1637-1644. https://doi.org/10.1534/genetics .117 .200782 .

Chandler, T. L., R. S. Pralle, J. R. R. Dórea, S. E. Poock, G. R. Oetzel, R. H. Fourdraine, and H. M. White. 2018. Predicting hyperketonemia by logistic and linear regression using test-day milk and performance variables in early-lactation Holstein and Jersey cows. J. Dairy Sci. 101:2476-2491. https://doi.org/10.3168/jds 2017-13209.

Cote, J. F., R. A. Curtis, B. J. McSherry, J. M. Robertson, and D. S. Kronfeld. 1969. Bovine ketosis: Frequency of clinical signs, complications and alterations in blood ketones, glucose and free fatty acids. Can. Vet. J. 10:179-187.

Cotter, D. G., R. C. Schugar, and P. A. Crawford. 2013. Ketone body metabolism and cardiovascular disease. Am. J. Physiol. Heart Circ. Physiol. 304:H1060-H1076. https://doi.org/10.1152/ ajpheart.00646.2012.

Crawford, P. A., J. R. Crowley, N. Sambandam, B. D. Muegge, E. K. Costello, M. Hamady, R. Knight, and J. I. Gordon. 2009. Regulation of myocardial ketone body metabolism by the gut microbiota during nutrient deprivation. Proc. Natl. Acad. Sci. USA 106:11276-11281. https://doi.org/10.1073/pnas.0902366106.

Daetwyler, H. D., B. Villanueva, and J. A. Woolliams. 2008. Accuracy of predicting the genetic risk of disease using a genome-wide approach. PLoS One 3:e3395. https://doi.org/10.1371/journal.pone .0003395

de Roos, A. P., H. J. van den Bijgaart, J. Hørlyk, and G. de Jong. 2007. Screening for subclinical ketosis in dairy cattle by Fourier transform infrared spectrometry. J. Dairy Sci. 90:1761-1766. https: //doi.org/10.3168/jds.2006-203.

DePeters, E. J., and L. W. George. 2014. Rumen transfaunation. Immunol. Lett. 162:69-76. https://doi.org/10.1016/j.imlet.2014.05 .009 .

Derakhshani, H., H. M. Tun, F. C. Cardoso, J. C. Plaizier, E. Khafipour, and J. J. Loor. 2017. Linking peripartal dynamics of ruminal microbiota to dietary changes and production parameters. Front. Microbiol. 7:2143. https://doi.org/10.3389/fmicb.2016.02143.

Difford, G. F., D. R. Plichta, P. Løvendahl, J. Lassen, S. J. Noel, O. Højberg, A.-D. G. Wright, Z. Zhu, L. Kristensen, H. B. Nielsen, B. Guldbrandtsen, and G. Sahana. 2018. Host genetics and the rumen microbiome jointly associate with methane emissions in dairy cows. PLoS Genet. 14:e1007580. https://doi.org/10.1371/journal .pgen.1007580.

Fan, P., C. D. Nelson, J. D. Driver, M. A. Elzo, and K. C. Jeong. 2019. Animal breed composition is associated with the hindgut microbiota structure and $\beta$-lactam resistance in the multibreed Angus-Brahman herd. Front. Microbiol. 10:1846. https://doi.org/ 10.3389/fmicb.2019.01846.

Faust, K., L. Lahti, D. Gonze, W. M. de Vos, and J. Raes. 2015. Metagenomics meets time series analysis: Unraveling microbial community dynamics. Curr. Opin. Microbiol. 25:56-66. https:// doi.org/10.1016/j.mib.2015.04.004.

Gebreyesus, G., M. S. Lund, L. Janss, N. A. Poulsen, L. B. Larsen, H. Bovenhuis, and A. J. Buitenhuis. 2016. Short communication: Multi-trait estimation of genetic parameters for milk protein com- position in the Danish Holstein. J. Dairy Sci. 99:2863-2866. https: //doi.org/10.3168/jds.2015-10501.

Geishauser, T., K. Leslie, D. Kelton, and T. Duffield. 1998. Evaluation of five cowside tests for use with milk to detect subclinical ketosis in dairy cows. J. Dairy Sci. 81:438-443. https://doi.org/10.3168/ jds.S0022-0302(98)75595-X.

Gilbert, J. A., M. J. Blaser, J. G. Caporaso, J. K. Jansson, S. V. Lynch, and R. Knight. 2018. Current understanding of the human microbiome. Nat. Med. 24:392-400. https://doi.org/10.1038/ nm. 4517 .

Goddard, M. 2009. Genomic selection: Prediction of accuracy and maximisation of long term response. Genetica 136:245-257. https: //doi.org/10.1007/s10709-008-9308-0.

Gohary, K., M. W. Overton, M. Von Massow, S. J. LeBlanc, K. D. Lissemore, and T. F. Duffield. 2016. The cost of a case of subclinical ketosis in Canadian dairy herds. Can. Vet. J. 57:728-732.

Goodrich, J. K., J. L. Waters, A. C. Poole, J. L. Sutter, O. Koren, R. Blekhman, M. Beaumont, W. Van Treuren, R. Knight, J. T. Bell, T. D. Spector, A. G. Clark, and R. E. Ley. 2014. Human genetics shape the gut microbiome. Cell 159:789-799. https://doi.org/10 $.1016 /$ j.cell.2014.09.053.

Henderson, G., F. Cox, S. Ganesh, A. Jonker, W. YoungGlobal Rumen Census Collaborators, and P. H. Janssen. 2015. Rumen microbial community composition varies with diet and host, but a core microbiome is found across a wide geographical range. Sci. Rep. 5:14567. https://doi.org/10.1038/srep14567.

Heuer, C., H. J. Luinge, E. T. Lutz, Y. H. Schukken, J. H. van der Maas, H. Wilmink, and J. P. Noordhuizen. 2001. Determination of acetone in cow milk by Fourier transform infrared spectroscopy for the detection of subclinical ketosis. J. Dairy Sci. 84:575-582. https: //doi.org/10.3168/jds.S0022-0302(01)74510-9.

Hildebrand, F., R. Tadeo, A. Y. Voigt, P. Bork, and J. Raes. 2014. LotuS: An efficient and user-friendly OTU processing pipeline. Microbiome 2:30. https://doi.org/10.1186/2049-2618-2-30.

Howie, B., J. Marchini, and M. Stephens. 2011. Genotype imputation with thousands of genomes. G3 (Bethesda) 1:457-470. https://doi .org/10.1534/g3.111.001198.

Hu, F., K. Furihata, M. Ito-Ishida, S. Kaminogawa, and M. Tanokura. 2004. Nondestructive observation of bovine milk by NMR spectroscopy: Analysis of existing states of compounds and detection of new compounds. J. Agric. Food Chem. 52:4969-4974.

Jami, E., and I. Mizrahi. 2012. Composition and similarity of bovine rumen microbiota across individual animals. PLoS One 7:e33306. https://doi.org/10.1371/journal.pone.0033306.

Jamrozik, J., A. Koeck, G. J. Kistemaker, and F. Miglior. 2016. Multiple-trait estimates of genetic parameters for metabolic disease traits, fertility disorders, and their predictors in Canadian Holsteins. J. Dairy Sci. 99:1990-1998. https://doi.org/10.3168/jds .2015-10505.

Jensen, H. B., J. W. Holland, N. A. Poulsen, and L. B. Larsen. 2012. Milk protein variants and isoforms identified in bovine milk representing extremes in coagulation properties. J. Dairy Sci. 95:28912903.

Jorritsma, R., S. J. Baldée, Y. H. Schukken, T. Wensing, and G. H. Wentink. 1998. Evaluation of a milk test for detection of subclinical ketosis. Vet. Q. 20:108-110.

Khafipour, E., S. Li, J. C. Plaizier, and D. O. Krause. 2009. Rumen microbiome composition determined using two nutritional models of subacute ruminal acidosis. Appl. Environ. Microbiol. 75:71157124. https://doi.org/10.1128/AEM.00739-09.

Kittelmann, S., C. S. Pinares-Patiño, H. Seedorf, M. R. Kirk, S. Ganesh, J. C. McEwan, and P. H. Janssen. 2014. Two different bacterial community types are linked with the low-methane emission trait in sheep. PLoS One 9:e103171. https://doi.org/10.1371/ journal.pone.0103171.

Klein, M. S., M. F. Almstetter, G. Schlamberger, N. Nürnberger, K. Dettmer, P. J. Oefner, H. H. D. Meyer, S. Wiedermann, and W. Gronwald. 2010. Nuclear magnetic resonance and mass spectrometry-based milk metabolomics in dairy cows during early and late lactation. J. Dairy Sci. 93:1539-1550. 
Koeck, A., J. Jamrozik, F. S. Schenkel, R. K. Moore, D. M. Lefebvre, D. F. Kelton, and F. Miglior. 2014. Genetic analysis of milk $\beta$-hydroxybutyrate and its association with fat-to-protein ratio, body condition score, clinical ketosis, and displaced abomasum in early first lactation of Canadian Holsteins. J. Dairy Sci. 97:72867292. https://doi.org/10.3168/jds.2014-8405.

Leahy, S. C., W. J. Kelly, E. Altermann, R. S. Ronimus, C. J. Yeoman, D. M. Pacheco, D. Li, Z. Kong, S. McTavish, C. Sang, S. C. Lambie, P. H. Janssen, D. Dey, and G. T. Attwood. 2010. The genome sequence of the rumen methanogen Methanobrevibacter ruminantium reveals new possibilities for controlling ruminant methane emissions. PLoS One 5:e8926. https://doi.org/10.1371/ journal.pone.0008926.

Lee, S., K. Cho, M. Park, T. Choi, S. Kim, and C. Do. 2016. Genetic parameters of milk $\beta$-hydroxybutyric acid and acetone and their genetic association with milk production traits of Holstein cattle. Asian-Australas. J. Anim. Sci. 29:1530-1540. https://doi.org/10 .5713 /ajas.16.0310.

Li, F., C. Li, Y. Chen, J. Liu, C. Zhang, B. Irving, C. Fitzsimmons, G. Plastow, and L. L. Guan. 2019. Host genetics influence the rumen microbiota and heritable rumen microbial features associate with feed efficiency in cattle. Microbiome 7:92. https://doi.org/10 .1186/s40168-019-0699-1.

Lynch, S. V., and O. Pedersen. 2016. The human intestinal microbiome in health and disease. N. Engl. J. Med. 375:2369-2379. https: //doi.org/10.1056/NEJMra1600266.

Madsen, P., and J. Jensen. 2007. A User's Guide to DMU: A Package for Analysing Multivariate Mixed Models. Version 6, release 4.7. Aarhus University, Tjele, Denmark.

Malmuthuge, N., and L. L. Guan. 2017. Understanding host-microbial interactions in rumen: Searching the best opportunity for microbiota manipulation. J. Anim. Sci. Biotechnol. 8:8. https://doi.org/ 10.1186/s40104-016-0135-3.

Maltecca, C., D. Lu, C. Schillebeeckx, N. P. McNulty, C. Schwab, C. Shull, and F. Tiezzi. 2019. Predicting growth and carcass traits in swine using microbiome data and machine learning algorithms. Sci. Rep. 9:6574. https://doi.org/10.1038/s41598-019-43031-x.

McArt, J. A. A., D. V. Nydam, and G. R. Oetzel. 2012. Epidemiology of subclinical ketosis in early lactation dairy cattle. J. Dairy Sci. 95:5056-5066.

Million, M., E. Angelakis, M. Maraninchi, M. Henry, R. Giorgi, R. Valero, B. Vialettes, and D. Raoult. 2013. Correlation between body mass index and gut concentrations of Lactobacillus reuteri, Bifidobacterium animalis, Methanobrevibacter smithii and Escherichia coli. Int. J. Obes. (Lond.) 37:1460-1466. https://doi.org/ 10.1038/ijo.2013.20.

Mulders, R. J., K. C. G. de Git, E. Schele, S. L. Dickson, Y. Sanz, and R. A. H. Adan. 2018. Microbiota in obesity: Interactions with enteroendocrine, immune and central nervous systems. Obes. Rev. 19:435-451. https://doi.org/10.1111/obr.12661.

Newell, C., M. R. Bomhof, R. A. Reimer, D. S. Hittel, J. M. Rho, and J. Shearer. 2016. Ketogenic diet modifies the gut microbiota in a murine model of autism spectrum disorder. Mol. Autism 7:37. https://doi.org/10.1186/s13229-016-0099-3.

Nielsen, N. I., N. C. Friggens, M. G. G. Chagunda, and K. L. Ingvartsen. 2005. Predicting risk of ketosis in dairy cows using in-line measurements of $\beta$-hydroxybutyrate: A biological model. J. Dairy Sci. 88:2441-2453. https://doi.org/10.3168/jds.S0022 -0302(05) 72922-2.

Oltenacu, P. A., and B. Algers. 2005. Selection for increased production and the welfare of dairy cows: Are new breeding goals needed? Ambio 34:311-315. https://doi.org/10.1579/0044-7447-34.4.311.

Penasa, M., D. Pretto, A. Varotto, and M. De Marchi. 2015. Heritability of milk $\beta$-hydroxybutyrate and its genetic association with milk yield and fat-to-protein ratio in Italian Holstein cows. In Book of Abstracts of the 21st National Congress of the Animal Science and Production Association (ASPA), June 9-12, Milan, Italy. Ital. J. Anim. Sci. 14(Suppl. 1):77.

Pryce, J. E., K. L. Parker Gaddis, A. Koeck, C. Bastin, M. Abdelsayed, N. Gengler, F. Miglior, B. Heringstad, C. Egger-Danner, K. F. Stock, A. J. Bradley, and J. B. Cole. 2016. Invited review:
Opportunities for genetic improvement of metabolic diseases. J. Dairy Sci. 99:6855-6873. https://doi.org/10.3168/jds.2016-10854.

Raboisson, D., M. Mounié, and E. Maigné. 2014. Diseases, reproductive performance, and changes in milk production associated with subclinical ketosis in dairy cows: A meta-analysis and review. J. Dairy Sci. 97:7547-7563. https://doi.org/10.3168/jds.2014-8237.

Ranaraja, U., K. Cho, M. Park, S. Kim, S. Lee, and C. Do. 2018. Genetic parameter estimation for milk $\beta$-hydroxybutyrate and acetone in early lactation and its association with fat to protein ratio and energy balance in Korean Holstein cattle. Asian-Australas. J. Anim. Sci. 31:798-803. https://doi.org/10.5713/ajas.17.0443.

Ross, E. M., P. J. Moate, L. C. Marett, B. G. Cocks, and B. J. Hayes. 2013. Metagenomic predictions: From microbiome to complex health and environmental phenotypes in humans and cattle. PLoS One 8:e73056. https://doi.org/10.1371/journal.pone.0073056.

Rothschild, D., O. Weissbrod, E. Barkan, A. Kurilshikov, T. Korem, D. Zeevi, P. I. Costea, A. Godneva, I. N. Kalka, N. Bar, S. Shilo, D. Lador, A. V. Vila, N. Zmora, M. Pevsner-Fischer, D. Israeli, N. Kosower, G. Malka, B. C. Wolf, T. Avnit-Sagi, M. Lotan-Pompan, A. Weinberger, Z. Halpern, S. Carmi, J. Fu, C. Wijmenga, A Zhernakova, E. Elinav, and E. Segal. 2018. Environment dominates over host genetics in shaping human gut microbiota. Nature 555:210-215. https://doi.org/10.1038/nature25973.

Sasson, G., S. Kruger Ben-Shabat, E. Seroussi, A. Doron-Faigenboim, N. Shterzer, S. Yaacoby, M. E. Berg Miller, B. A. White, E. Halperin, and I. Mizrahi. 2017. Heritable bovine rumen bacteria are phylogenetically related and correlated with the cow's capacity to harvest energy from its feed. MBio 8:e00703-17. https://doi.org/ 10.1128/mBio.00703-17.

Schären, M., J. Frahm, S. Kersten, U. Meyer, J. Hummel, G. Breves, and S. Dänicke. 2018. Interrelations between the rumen microbiota and production, behavioral, rumen fermentation, metabolic, and immunological attributes of dairy cows. J. Dairy Sci. 101:46154637. https://doi.org/10.3168/jds.2017-13736.

Shabat, S. K., G. Sasson, A. Doron-Faigenboim, T. Durman, S. Yaacoby, M. E. Berg Miller, B. A. White, N. Shterzer, and I. Mizrahi. 2016. Specific microbiome-dependent mechanisms underlie the energy harvest efficiency of ruminants. ISME J. 10:2958-2972. https: //doi.org/10.1038/ismej.2016.62.

Sundekilde, U. K., N. Poulsen, L. B. Larsen, and H. C. Bertram. 2013. Nuclear magnetic resonance metabonomics reveals strong association between milk metabolites and somatic cell count in bovine milk. J. Dairy Sci. 96:291-299.

Turnbaugh, P. J., R. E. Ley, M. A. Mahowald, V. Magrini, E. R. Mardis, and J. I. Gordon. 2006. An obesity-associated gut microbiome with increased capacity for energy harvest. Nature 444:1027-1031. https://doi.org/10.1038/nature05414.

Ulrich, E. L., H. Akutsu, J. F. Doreleijers, Y. Harano, Y. E. Ioannidis, J. Lin, M. Livny, S. Mading, D. Maziuk, Z. Miller, E. Nakatani, C. F. Schulte, D. E. Tolmie, R. K. Wenger, H. Yao, and J. L. Markley. 2008. BioMagResBank. Nucleic Acids Res. 36:D402-D408.

van der Drift, S. G. A., K. J. E. van Hulzen, T. G. Teweldemedhn, R. Jorritsma, M. Nielen, and H. C. M. Heuven. 2012. Genetic and non-genetic variation in plasma and milk $\beta$-hydroxybutyrate and milk acetone concentrations of early-lactation dairy cows. J. Dairy Sci. 95:6781-6787. https://doi.org/10.3168/jds.2012-5640.

VanRaden, P. M. 2008. Efficient methods to compute genomic predictions. J. Dairy Sci. 91:4414-4423.

Veerkamp, R. F. 2002. Feed intake and energy balance in lactating animals. Proc. Seventh World Congress Genet. Appl. Livest. Prod. Session 10. Aug. 19-23. Montpellier, France.

Wallace, R.J., G. Sasson, P.C. Garnsworthy, I. Tapio, E. Gregson, P. Bani, P. Huhtanen, A.R. Bayat, F. Strozzi, F. Biscarini, T.J. Snelling, N. Saunders, S.L. Potterton, J. Craigon, A. Minuti, E. Trevisi, M.L. Callegari, F.P. Cappelli, E.H. Cabezas-Garcia, J. Vilkki, C. Pinares-Patino, K.O. Fliegerová, J. Mrázek, H. Sechovcová, J. Kopečný, A. Bonin, F. Boyer, P. Taberlet, F. Kokou, E. Halperin, J.L. Williams, K.J. Shingfield, and I. Mizrahi. 2019. A heritable subset of the core rumen microbiome dictates dairy cow productivity and emissions. Sci. Adv. 5:eaav8391. https://doi.org/ $10.1126 /$ sciadv.aav8391. 
Wang, Q., G. M. Garrity, J. M. Tiedje, and J. R. Cole. 2007. Naive Bayesian classifier for rapid assignment of rRNA sequences into the new bacterial taxonomy. Appl. Environ. Microbiol. 73:5261-5267.

Wilmink, J. B. M. 1987. Adjustment of test-day milk, fat and protein yield for age, season and stage of lactation. Livest. Prod. Sci. 16:335-348. https://doi.org/10.1016/0301-6226(87)90003-0.

Wishart, D. S., C. Knox, A. C. Guo, R. Eisner, N. Young, B. Gautam, D. D. Hau, H. Psychogios, E. Dong, S. Bouatra, R. Mandal, I. Sinelnikov, J. Xia, L. Jia, J. A. Cruz, E. Lim, C. A. Sobsey, S. Shravastava, P. Huang, P. Liu, L. Fang, J. Peng, R. Fradette, D. Cheng, D. Tzur, M. Clements, A. Lewis, A. De Souza, A. Zuniga, M. Dawe, Y. Xiong, D. Clive, R. Greiner, A. Nazyrova, R. Shaykhutdinov, L. Li, H. J. Vogel, and I. Forsythe. 2009. HMDB: A knowledgebase for the human metabolome. Nucleic Acids Res. 37:D603-D610.

Zhou, M., E. Hernandez-Sanabria, and L. L. Guan. 2009. Assessment of the microbial ecology of ruminal methanogens in cattle with different feed efficiencies. Appl. Environ. Microbiol. 75:6524-6533. https://doi.org/10.1128/AEM.02815-08.

Zhu, Z., L. Kristensen, G. F. Difford, M. Poulsen, S. J. Noel, W. Abu Al-Soud, S. J. Sørensen, J. Lassen, P. Løvendahl, and O. Højberg.
2018. Changes in rumen bacterial and archaeal communities over the transition period in primiparous Holstein dairy cows. J. Dairy Sci. 101:9847-9862. https://doi.org/10.3168/jds.2017-14366.

\section{ORCIDS}

Grum Gebreyesus @ https://orcid.org/0000-0003-4757-3060

Gareth F. Difford @ https://orcid.org/0000-0002-6792-8722

Bart Buitenhuis @ https://orcid.org/0000-0002-4953-3081

Samantha Joan Noel @ https://orcid.org/0000-0003-4529-9598

Ole Højberg @ https://orcid.org/0000-0002-4947-4536

Damian R. Plichta @ https://orcid.org/0000-0002-6555-2557

Zhigang Zhu • https://orcid.org/0000-0001-5617-4825

Nina A. Poulsen ํㅏ https://orcid.org/0000-0001-9983-9663

Ulrik K. Sundekilde (® https://orcid.org/0000-0003-4849-0996

Peter Løvendahl ๑ https://orcid.org/0000-0002-9852-2944

Goutam Sahana @ https://orcid.org/0000-0001-7608-7577 